Stevenson HC. The effect of anesthetic agents on the human immune response. Anesthesiology 1990; 75: 542-52.

5 Lorenz IH, Kolbitsch C, Lass-Florl C, et al. Routine handling of propofol prevents contamination as effectively as does strict adherence to the manufacturer's recommendations. Can J Anesth 2002; 49: 347-52.

\section{Use of the Endoflex@ endotracheal tube as a stylet-free alternative in Glidescope intubations}

\section{To the Editor:}

The Glidescope ${ }^{\circledR}$ Videolaryngoscope (GVL; Verathon Inc., WA, USA) has been widely used for intubation in recent years. Incorporating a high-resolution camera into its patented, $60^{\circ}$ angulated blade, it allows for good visualisation of the glottis, even in patients with more difficult airways. Due to the unique angulation of the blade, a dedicated manufacturer provided the stylet (Glidescope ${ }^{\circledR}$ Rigid Stylet, Verathon Medical, Bothell, WA, USA) utilized to facilitate intubation. ${ }^{\mathrm{A}}$ However, there have been reports highlighting the complications of utilizing such rigid stylets in Glidescope intubations. These difficulties include soft palate, pharyngeal, and tonsillar lacerations and perforations. ${ }^{1-3}$ The Endoflex ${ }^{\circledR}$ endotracheal tube (ETT) (Merlyn Associates, Tustin CA, USA) is a single lumen, disposable ETT with an in-built flexing mechanism and a friction lock that allows for easy articulation of its distal tip over a range of angles, without the need for a separate stylet. ${ }^{\mathrm{B}}$ We found that Endoflex ${ }^{\circledR}$ ETT's distal articulation closely followed the $60^{\circ}$ angle of the GVL and the Glidescope Rigid Stylet ${ }^{\circledR}$ (Figure). Consequently, we explored its use, in our institution, as an alternative to the Rigid Stylet in Glidescope intubations.

Our intubation technique remains fairly similar to the traditional means of intubation with the GVL. First, the Glidescope blade is inserted in the midline, with direct visualization of the passage of the blade, and the laryngeal view is optimized before the Endo-

A Glidescope ${ }^{\circledR}$ Video Laryngoscopes, Verathon Inc, WA, USA. Available from http://www.verathon.com/glidescope_products.htm (accessed April 2008)

B EndoFlex ${ }^{\circledR}$ Endotracheal Tube, Merlyn Medical, Tustin CA, USA. Available from http://www.merlynmedical.com/ endoflex.php (accessed April 2008).

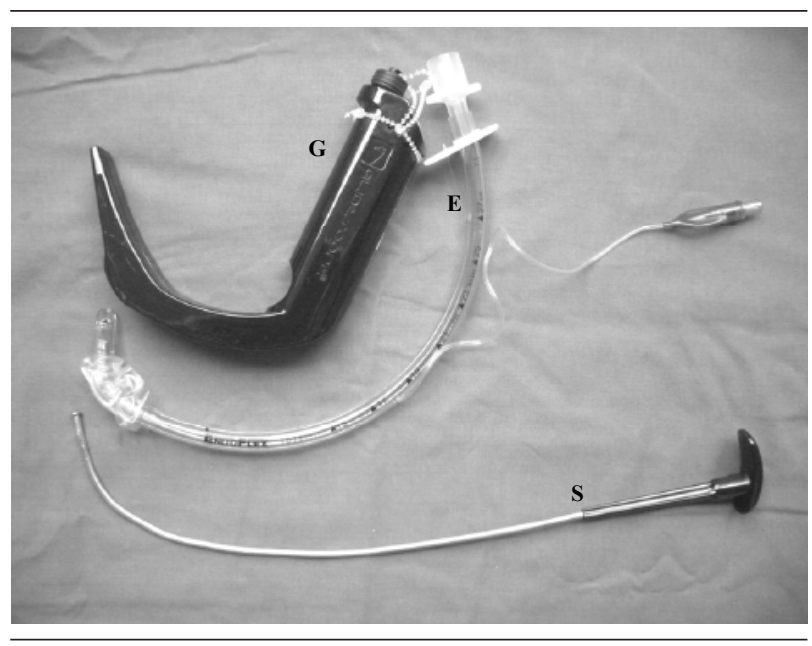

FIGURE The Glidescope ${ }^{\circledR}$ Videolaryngoscope (G), fully articulated Endoflex ${ }^{\circledR}$ endotracheal tube (E) and the Glidescope ${ }^{\circledR}$ Rigid Stylet (S).

flex ${ }^{\circledR}$ ETT is introduced into the oral cavity, also in the midline. Next, by applying traction on the friction lock mechanism, the distal articulating tip of the Endoflex ${ }^{\circledR}$ is flexed, and the ETT is advanced under direct vision until it comes into the field of view of the Glidescope. In order to minimize risks of airway trauma, visualization of the ETT tip, as it passes through the oropharynx, is important. The Endoflex®, with its flexible, articulating tip (allowing for changes in angulation if needed to facilitate intubation), is then directed to the glottic opening. Once the tip of the Endoflex ${ }^{\circledR}$ has been passed beyond the vocal cords, the friction lock is released, thus allowing the Endoflex ${ }^{\circledR}$ to passively return to its normal curvature aiding passage into the trachea. The tube is then advanced under vision to complete intubation before the Glidescope is removed.

The Endoflex® ETT appears to be a promising alternative to the Rigid Stylet in Glidescope intubations, with its main advantage being the possible reduction or elimination of airway injuries associated with the use of rigid stylets. The flexible distal articulating tip, which flexes over a range of angles, also appears well suited to Glidescope ${ }^{\circledR}$ intubations. Though significant, airway trauma attributed to use of the Glidescope remains rare in our centre and consists, for the most part, of case reports in published literature. Perhaps the Endoflex ${ }^{\circledR}$ ETT will provide a welcome alternative in the airway arsenal of the anesthesiologist. 
Darren Phua mmed (Anaes)

Chin Foong Wang Mmed (Anaes)

Chee Seng Yoong mued (Anaes)

Changi General Hospital, Singapore

E-mail: darren_phua@cgh.com.sg

No financial associations or competing interests to be declared.

Accepted for publication April 18, 2008.

\section{References}

1 Hsu WT, Hsu SC, Lee YL, Huang JS, Chen CL.

Penetrating injury of the soft palate during Glide-

Scope ${ }^{\circledR}$ intubation. Anesth Analg 2007; 104:

1609-10.

2 Malik AM, Frogel JK. Anterior tonsillar pillar perforation during Glidescope ${ }^{\circledR}$ video laryngoscopy. Anesth Analg 2007; 104: 1610-1.

3 Cooper RM. Complications associated with the use of the GlideScope videolaryngoscope. Can J Anesth 2007; 54: 54-7. 